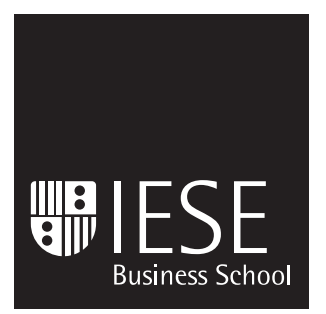

Anselmo Rubiralta Center

Working Paper

WP no 621

for Globalization and Strategy

March, 2006

University of Navarra

\title{
A FORMAL EVALUATION OF THE PERFORMANCE OF DIFFERENT CORPORATE STYLES IN STABLE AND TURBULENT ENVIRONMENTS
}

\author{
Adrián A. Caldart \\ Joan Enric Ricart
}


The Anselmo Rubiralta Center for Globalization and Strategy aims to be an international benchmark for companies, universities, business schools and governments. It promotes the exchange of ideas in the area of globalization and international strategy.

The Center's main objectives are to:

- Develop a conceptual structure that will help companies to understand and manage the impact of globalization and develop strategies of internationalization;

- Generate and disseminate new knowledge in this field;

- Develop new, high-quality teaching materials.

www.iese.edu/globalcenter 


\title{
A FORMAL EVALUATION OF THE PERFORMANCE OF DIFFERENT CORPORATE STYLES IN STABLE AND TURBULENT ENVIRONMENTS
}

\author{
Adrián A. Caldart* \\ Joan Enric Ricart**
}

\begin{abstract}
The notion of "parenting styles", introduced by Goold, Campbell and Alexander, has been widely acknowledged by the Corporate Strategy literature as a good broad description of the different ways in which corporate managers choose to manage and organize multibusiness firms. The purpose of this paper is to present a formal test of the relationship between parenting style and performance. For this test, we developed a set of agent-based simulations using the Performance Landscapes framework, which captures and describes the evolution of firms led by different parenting styles in business environments with different levels of complexity and dynamism.
\end{abstract}

We found that the relative performance of each style is contingent upon the characteristics of the environment in which the firm operates. In less complex business environments, the Strategic Planning style outperforms the Strategic Control and Financial Control styles. In highly complex and highly dynamic environments, by contrast, the Strategic Control style performs best.

Our results also demonstrate the importance of planning and flexibility at the corporate level and so contribute to the wider debate on Strategic Planning vs. Emergent Strategies.

\footnotetext{
* Professor Warwick Business School

** Professor of General Management, IESE
}

Keywords: Corporate Strategy, Parenting Styles, Agent-based models. 


\section{A FORMAL EVALUATION OF THE PERFORMANCE OF DIFFERENT CORPORATE STYLES IN STABLE AND TURBULENT ENVIRONMENTS*}

\section{Introduction}

Corporate-level strategy, or simply "corporate strategy", is a topic that has received much attention since the very early days of the strategic planning field. Andrews (1971) defined corporate strategy as "the pattern of decisions that determined a company's goals, produced the principle policies for achieving these goals, and defined the range of businesses the company was to pursue". Porter (1987) referred to corporate strategy as "what makes the corporate whole add up to more than its business parts". The major influence of Corporate-level decisions on the overall strategy of a multibusiness firm has been widely reported in the strategy literature (Porter, 1987; Goold, Campbell and Alexander, 1994; Brush and Bromiley, 1997; Collis and Montgomery, 1997; Chang and Singh, 2000; Bowman and Helfat, 2001; McGahan and Porter; 2002; Ruefli and Wiggins, 2003.)

There are certain broad patterns in the way firms manage jurisdiction over decisions between the corporate level and business units and exercise strategic control when implementing their corporate strategies. Porter (1987) identified four different "concepts of corporate strategy", which he labeled Portfolio Planning, Restructuring, Transferring Skills and Sharing Activities. Goold, Campbell and Alexander (1987) also observed different patterns or parenting styles, which they labeled Strategic Planning, Financial Control and Strategic Control.

Goold et al.'s (1987) idea of parenting styles has been highly influential in the strategy literature (Chandler, 1991; DeWit and Meyer, 2005; Grant, 2005; McGee, Thomas and Wilson, 2005). However, we are not aware of any studies to date aimed at developing formal models to understand the inner workings of parenting styles and, more importantly, how they affect performance.

This paper addresses this issue by developing an agent-based simulation model that captures the central features of Goold et al.'s parenting styles, the relationships between those features, and their impact on firm performance over time.

\footnotetext{
* We gratefully acknowledge support for this research from Warwick Business School and from IESE Business School's Anselmo Rubiralta Center for Globalization and Strategy
} 
We found that the relative performance of each parenting style is highly contingent on the characteristics of the business environment in which the firm operates. In less complex environments demanding less interdependence between a firm's different businesses, the Strategic Planning style outperforms the Strategic Control and Financial Control styles. These results hold for firms operating in both stable and dynamic environments. However, as environmental complexity increases, firms respond by increasing the complexity of their design. The Strategic Planning style is recommended only in stable business environments; in highly dynamic and highly complex business environments (referred to in this study as "turbulent" environments), the Strategic Control style performs best, while Strategic Planning obtains the worst results, being outperformed by Financial Control.

These findings not only allow us to assess the relative merits of different styles but also have broader implications. They enable us to understand how a firm's parenting style, the quality of its managers' cognitive representations and the architectural design the firm chooses for the development of its corporate strategy interact with one another, and how such interaction impacts on the firm's performance. Our conclusions make it possible to assess the contingent importance of sound planning vs. strategic flexibility at the corporate level, thus bringing novel elements to the debate between the merits of planning vs. emergence (Mintzberg, 1990; Ansoff, 1991). Finally, our results give formal support to previous descriptive work arguing the superiority of loose, self-organized collaboration between business units over centrally imposed, tightly coupled collaboration initiatives.

This paper starts with a discussion of Goold et al.'s ideas of parent organization and parenting styles. Then, we introduce and explain a formal agent-based simulation model of corporate strategy that explores the performance of Goold et al.'s parenting styles in different environments. In the following section, the results of the simulations are analyzed. After that, we discuss our findings and present our conclusions. Finally, we suggest further avenues for research on corporate strategy.

\section{Literature Review}

Several well known scholars have addressed the issue of how to manage and organize firms to create corporate advantage, i.e., to create value through corporate-level decisions (Porter, 1987, Goold, Campbell and Alexander, 1987, 1994, 1995; Prahalad and Hamel, 1990, Markides and Williamson, 1994; Collis and Montgomery, 1998; Goold and Campbell, 2002).

In particular, Goold et al. (1987, 1994) developed the highly influential idea of parenting advantage. They state that the corporate center or parent organization of a multibusiness firm is an intermediary between investors and businesses, competing not only with other parent organizations but with Investment and Mutual Funds. Corporate strategy, therefore, makes sense not only if the value provided by the corporate center is greater than its inherent cost but also if the center is the best possible parent for that particular business. That is the case when the parent's skills and resources fit well with the business's needs and opportunities.

Goold et al. also examined the issue of fit between decisions made by the parent organization and its businesses in terms of the parent's overall behavior. They discerned certain broad patterns of parenting which represent basically different parenting philosophies. They referred to these patterns as parenting styles. Styles differ primarily in planning influence and control influence (Goold et al., 1994). Planning influence refers to the parent's approach to strategy 
formulation; it ranges from low influence (highly decentralized) to high influence (closely involved and influential) (Goold et al., 1994).

Control influence refers to the parent's approach to the control process. At one extreme are the parents that put the emphasis on short-term financial targets; at the other extreme are those that focus primarily on strategic goals and so are more flexible with respect to short-term financial targets. Between these two extremes are firms that try to strike a balance between financial and strategic targets. Based on multibusiness firms' different approaches to planning and control, Goold et al. identify three parenting styles: Strategic Planning, Financial Control and Strategic Control.

Strategic Planning (SP). Strategic Planning parents are closely involved in the formulation of plans and decisions. They provide a clear overall sense of direction, within which their businesses develop their strategies. They establish detailed planning processes, make contributions of substance to strategic thinking, and may have a corporate strategy or mission guiding and coordinating developments across the business units. In most but not all cases, Strategic Planning companies are heavily involved in encouraging cooperation and coordination between businesses. The control process in Strategic Planning companies stresses the long-term health and development of the businesses as top priority. Performance targets are set in broader, more strategic terms. Annual financial targets are seen as being less important than the longer-term strategic objectives.

Financial Control (FC). Financial Control parents are strongly committed to decentralized planning. They structure their businesses as stand-alone units with as much autonomy as possible and with full responsibility for formulating their own strategies and plans. Therefore, the M-form is the predominant form or organization among firms following this style, though other organizational forms are not precluded.

Decisions are "owned" by the businesses. The budget is the basic means of control and becomes, almost by default, the primary instrument of planning. Each budget, as a contract between the corporate office and the business unit, is treated on its own merits and not in relation to a larger overall strategic plan. Current financial performance is the critical measure of achievement.

Strategic Control (SC). Strategic Control parents "seek a balance between the extremes of the other two styles" (Goold et al., 1994). They expect businesses to put forward strategies, plans and proposals in a "bottom-up" fashion, but proposals are sanctioned at the corporate level if and only if they satisfy the right balance of strategic and financial criteria. Businesses are usually encouraged to work together to achieve synergy benefits, but within organizational structures and responsibilities that stress individual business unit performance.

If circumstances have changed since the plan was made, it is accepted that business managers may not be able to deliver on their original targets and that a revised forecast may be needed. Thus, Strategic Control companies seek a balance between financial and strategic targets.

Table 1 provides a summary of the central features of each parenting style. 
Table 1. Goold et al.'s (1987) Parenting Styles

\begin{tabular}{|c|l|l|}
\hline $\begin{array}{c}\text { Parenting Style/ } \\
\text { Features }\end{array}$ & \multicolumn{1}{|c|}{$\begin{array}{c}\text { Planning } \\
\text { Influence }\end{array}$} & \multicolumn{1}{c|}{$\begin{array}{c}\text { Control } \\
\text { Influence }\end{array}$} \\
\hline Strategic Planning & $\begin{array}{l}\text { Centralized at the } \\
\text { corporate level, } \\
\text { top-down }\end{array}$ & $\begin{array}{l}\text { Mainly Strategy } \\
\text { Long-term }\end{array}$ \\
\hline Strategic Control & $\begin{array}{l}\text { Centralized decision } \\
\text { led by "bottom-up" } \\
\text { initiatives }\end{array}$ & $\begin{array}{l}\text { Strategic and Financial. } \\
\text { Flexible to changing } \\
\text { circumstances }\end{array}$ \\
\hline Financial Control & $\begin{array}{l}\text { Decentralized at the } \\
\text { business level }\end{array}$ & Short-term Financial \\
\hline
\end{tabular}

\section{A model of parenting styles}

To better understand the performance implications of different parenting styles, we introduce a model of the evolution of firms led by corporate strategies defined by Goold et al.'s parenting styles. With the help of an agent-based simulation, we study, for each parenting style, how emergent properties deriving from the interaction between the different parts of the firm affect the firm's evolution and performance in environments of differing complexity and dynamism.

This model builds on the tradition of behavioral evolutionism (March and Simon, 1958; Cyert and March, 1963; Nelson and Winter, 1982). Behavioral evolutionism conceives of firms as problem-solving entities involved in processes of search and discovery. Unlike the classic theory of the firm, which treats firms as omniscient rational systems, behavioral evolutionism assumes that, while searching for solutions to their problems, firms adopt some form of adaptive behavior. While adapting, they consider only a limited number of decision alternatives, due to bounded rationality (Simon, 1997). The choice of the set of alternatives depends on certain features of organizational structure and the locus of the search responsibility and is heavily conditioned by the rules within which such choice occurs (Cyert and March, 1963).

Brabazon and Matthews (2002) state that the concept of adaptive search is meaningful only in the context of a defined search space, a means for traversing such space, and the ability to determine the quality of a proposed solution. Kauffman's NK model (Kauffman, 1993) provides such a context and so has become the mainstream formal modeling strategy for recent work rooted in the evolutionary tradition. Work based on the NK model has been developed and adapted by organization theorists to model organizational problem-solving processes showing features such as bounded rationality in the consideration of alternatives, the existence of interdependencies between subunits that can be manipulated by planning systems, decision making based on analogy, and the existence of decision rules that bound the set of possible choices (Levinthal, 1997; McKelvey, 1999; Gavetti, and Levinthal 2000; Rivkin, 2000; Caldart and Ricart, 2004; Gavetti, Levinthal and Rivkin, 2005; Siggelkow and Rivkin, 2005).

In the NK model, organizations adapt by modifying their existing form in an attempt to enhance their performance in a performance landscape (Levinthal, 1997; Siggelkow and Levinthal, 2005). A performance landscape consists of a multidimensional space in which each attribute of the organization is represented by a dimension of the space and a final dimension indicates the performance level of the organization. 
In the NK model, the parameter $\mathrm{N}$ expresses the number of attributes that characterize the entity (in our case, the attributes are policy choices and the entity is a business firm). The overall behavior of the firm is characterized by the vector $\mathrm{X}\left\{\mathrm{X}_{1}, \mathrm{X}_{2}, \ldots, \mathrm{X}_{\mathrm{N}}\right\}$, where each $\mathrm{X}_{\mathrm{i}}$ takes the value of 0 or 1 . Then, the performance landscape consists of a map of the $2^{\mathrm{N}}$ possible performance values associated with each of the policy choices the firm can make.

The parameter $\mathrm{K}$ is a measure of the number of policies that affect a particular policy's contribution to performance. In other words, $\mathrm{K}$ is a measure of the degree of interdependence between the firm's different policies. Then, each attribute of the vector $\mathrm{X}$ can take on $2^{\mathrm{K}+1}$ different performance values, depending on the value of the attribute itself (either 1 or 0 ) and the value of the $\mathrm{K}$ other attributes with which it interacts.

Interdependencies between attributes affect the topography of the performance landscape. In the extreme case of $\mathrm{K}=0$, the contribution of each policy is independent of other policies. Therefore, an absolute optimum can be reached simply by optimizing decisions at the policy level and aggregating their contribution to performance. In this situation, we say that the landscape tends to assume a single-peak configuration.

As the value of $\mathrm{K}$ increases, so does the ruggedness of the landscape, i.e., the landscape will have more local maxima or "peaks". In a rugged landscape, actors are assumed to be intelligent, but their intelligence is local to their position on the landscape (March and Simon, 1958; Cyert and March, 1963). They are assumed to be able to identify the positive and negative gradients around their current position, but not of making similar judgments about more distant positions (Levinthal and Warglien, 1999). In this case, firms may become trapped in competency traps (Levitt and March, 1988).

In light of the above, in order to develop a simulation model of adaptive firms led by different corporate styles we must: a) generate the performance landscapes over which adaptive search processes take place; b) determine how firms position themselves at the beginning of the search process and how they evolve over time according to their parenting style.

\subsection{Modeling the Performance Landscape}

Modeling the performance landscape implies mapping the $2^{\mathrm{N}}$ performance values associated with each possible configuration of attributes, represented by the vector $\mathrm{X}\left\{\mathrm{X}_{1}, \mathrm{X}_{2}, \ldots, \mathrm{X}_{\mathrm{N}}\right\}$, that firms can choose during their evolution. In this paper we follow Rivkin (2000) in calling each possible complete configuration of $\mathrm{N}$ attributes a "strategy". In the NK model the performance associated with each strategy equals the average of the contribution to performance of each of the $\mathrm{N}$ attributes (Rivkin, 2000).

\subsubsection{Corporate and business decisions}

As we want to focus on parenting styles, we need to develop a model that links corporate decisions to business unit decisions. Corporate decisions set the parameters of decisions made in the business units, imposing restrictions on decision makers at that level (Milgrom and Roberts 1992). We operationalized this relationship between decision levels by clustering the $N$ attributes within the vector in $U$ subgroups, each of which represents a business unit of a multibusiness firm. Within each subgroup or division, D attributes represent the decisions made within that business unit. 
In the model, we assume that all business units have an equal weight on performance and that individual decisions made within each business unit also have an equal weight on performance. In our simulations, we model a firm with $\mathrm{N}=9$, with variables clustered in three business units, U1, U2 and U3. Therefore, we can model $2^{3}$ different corporate strategies. Each business unit can then make $2^{3}$ business-level decisions over three attributes: D1, D2 and D3. Decisions made at the corporate level are related to decisions made within the business unit by a simple "majority rule" (Gavetti, Levinthal and Rivkin, 2005). For instance, if the corporate decision for $\mathrm{U} 1$ is "1", the possible decisions within U1 that fit such corporate decision are only $\{111\}$, $\{110\},\{011\}$ or $\{101\}$. Figure 1 provides an example of how the majority rule works.

Figure 1. Example of decision making at Corporate and Divisional Levels
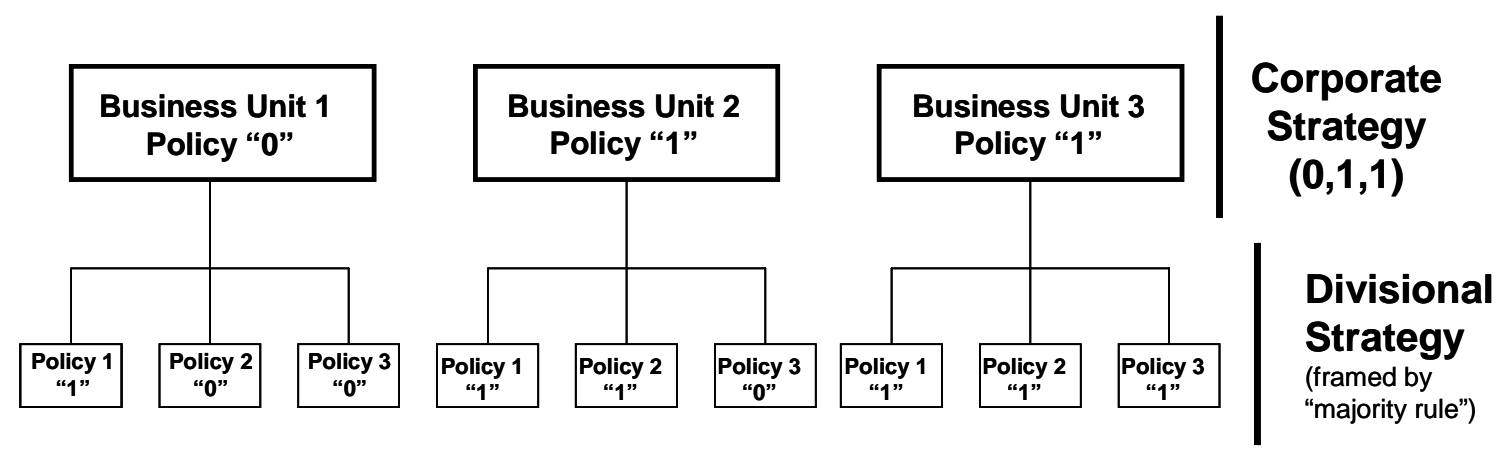

\subsubsection{Computing the performance of individual attributes}

In order to calculate the performance associated with each strategy, we need to compute the performance contribution of each of the firm's attributes. To do that, we need to model how interdependencies between decisions at the corporate level and at the business level impact on the performance contribution of the firm's attributes. Additionally, we need to determine how corporate decisions affect business-level decisions. Following Gavetti, Levinthal and Rivkin (2005), we modified Kauffman's basic framework by replacing parameter K by two parameters, $K_{w}$ and $K_{B}$. Parameter $K_{w}$ captures interdependencies within each business unit. Parameter $K_{B}$ measures the degree of interdependence of decisions made by the different business units.

The value of one attribute within each business unit depends on the value of the $K_{w}$ successive elements of the string. Suppose that BU1's policy choices are represented by the vector $\{0,1,1\}$. If $K_{W}=1$, this means that the performance value of the first attribute included in the string (in our case, policy decisions) depends on the value of the second element, the performance value of the second element depends on the value of the third, and the performance value of this depends on the value of the first element. This circular treatment of the vector when determining interdependencies between variables in order to compute performance values is taken from Kauffman (1993).

A random number, generated from a uniform distribution ranging from 0 to 1 , is assigned to constitute the performance contribution of a 0 in the first attribute when there is a 1 in the second element. A different random number is generated when there is a 0 in the first element and a 0 in the second element. Thus, each policy can take $2^{\mathrm{Kw}+1}$ values, depending on the value of the policy itself (either 0 or 1 ) and the value of the $K_{w}$ other attributes with which it 
interacts. The procedure is repeated for each attribute of the three divisions. In this way we obtain the performance value of each policy within each business unit, taking into account the impact of other variables within the same division.

In order to complete the computation of the performance contribution of each individual attribute, we must assess the impact of the interaction between business units on such performance. We assumed that every business unit has an impact on the others' performance value. This effect is operationalized by treating corporate decisions as variables (Gavetti, 1999). Each business unit can take only two possible values: zero or one. The overall corporate strategy is represented by the value of the policies corresponding to the three divisions, for example $\{1,1,0)$. Then, a random number, generated from the uniform distribution ranging from 0 to 1 is assigned to represent the performance contribution of D1 in U1, when U1 takes a one, U2 takes a one and U3 a zero.

The global performance contribution of a given policy variable is calculated according to the following formula (Gavetti, 1999):

$$
\mathrm{F}_{\mathrm{i}}=\left(1-\mathrm{K}_{\mathrm{B}}\right) * \mathrm{~F}_{\mathrm{Wi}}+\mathrm{K}_{\mathrm{B}} * \mathrm{~F}_{\mathrm{Bi}},
$$

where $F_{i}$ is the global fitness contribution of variable $i, F_{W i}$ its contribution taking into account interdependencies within the division, and $\mathrm{F}_{\mathrm{Bi}}$ the effect of interdependences between business units. The parameter $K_{B}$ tunes the degree of decomposability between the decisions made by the different business units. $K_{B}$ can take any value between zero and one. If $K_{B}=0$, the contribution of every business unit to the firm's overall performance is independent of decisions made within other business units. In this case, we can say that there is full decomposability between decisions made by different business units. As the value of $K_{B}$ increases, the decomposability of the firm's problems is reduced, because business units' contribution to performance is affected by other divisions' decisions.

A particular firm's overall performance is equal to the average of the performance contributions of its $\mathrm{N}$ attributes, calculated as explained above.

\subsection{Modeling the Parenting Style}

After developing the performance landscape over which firms' adaptive evolution takes place, we need to model planning influence and control influence for each of the three parenting styles. First, we discuss planning influence, explaining how firms choose their positioning at the beginning of the simulation. Then, we describe control influence.

\subsubsection{Modeling Planning influence}

Modeling planning influence is about setting the rules that determine the initial positioning of firms led by the different parenting styles in the simulation model. According to Goold et al., companies following the Strategic Planning and Strategic Control parenting styles develop their corporate strategy at the corporate level. Financial control firms, in contrast, do not follow an overall corporate strategic plan.

\footnotetext{
'Although Strategic Control firms leave more room for "bottom-up" strategic proposals coming from the business units, they still make the decision at the corporate level.
} 
In order to model strategic choice at $\mathrm{M}_{0}$ in the simulation model, we proceeded in the following way. As $\mathrm{N}=9$ and $\mathrm{U}=3$, the firms we modeled can only follow $2^{3}$ "generic" corporate strategies. Each of these strategies has the effect of bounding the firm's evolution within the sub-area of the performance landscape that satisfies the majority rule imposed by the specific corporate strategy the firm has chosen. We computed the expected value of the performance that the firms can achieve in each of those sub-areas of the performance landscape corresponding to the eight possible corporate strategies that a firm can choose. Then, we used that information to model planning influence for the different styles in the following way:

a) Strategic Planning and Strategic Control styles. At the beginning of the experiment, the computer program randomly assigns to each firm a number $\mathrm{C}$ of possible corporate strategies, with $0<C<=8$. Simulated firms position themselves at $\mathrm{M}_{0}$, choosing the corporate strategy that has associated with it the highest expected value among the possibilities assigned by the computer.

Although the corporate strategies represented and chosen by the firms at $\mathrm{M}_{0}$ are grounded on the actual landscape, they are based only on knowledge of the expected values of the performances associated with the respective sub-areas of the landscape. These representations are not a good predictor of the performance of specific strategies in the sub-set of the performance landscape chosen by the firm. Although the chosen corporate strategy is, on average, the best of the $C$ strategies that firms can represent, this does not mean that all the points in the subset of the performance landscape chosen by the firm are attractive. This design is consistent with the assumption of bounded rationality of firms as adaptive rational systems (March and Simon, 1958; Cyert and March, 1963; Levitt and March, 1988; Levinthal and March, 1993; Simon, 1997). In our case, simulated firms might experience a competency trap (Levitt and March, 1988), despite evolving in a subset that is, on average, relatively attractive.

b) Financial Control Styles. As these firms are not led by an overall plan, we assigned them one of the eight possible corporate strategies randomly at $\mathrm{M}_{0}$.

\subsubsection{Modeling Control Influence}

As mentioned above, control influence refers to the parent's approach to the exercise of strategic control. In the simulation, the different approaches are embedded in the rules that firms follow during their evolution.

Once positioned in the performance landscape at $\mathrm{M}_{0}$, in all cases, firms evolve following a local search strategy. In Kauffman's model, local search takes place when the set of business attributes are varied only incrementally. In our model, local search works as follows: from an initial configuration of the vector $\mathrm{X}$, for example $\{0,1,1,1,1,1,1,0,0\}$, with an associated performance value $\mathrm{P}_{0}$, the firm explores a configuration adjacent to the initial one, for example $\{1,1,1,1,1,1,1,0,0\}$, with an associated performance value $P_{1}$. If $P_{1}>P_{0}$, the firm adopts the new form $\{1,1,1,1,1,1,1,0,0\} \quad P_{1}$ and from there explores another adjacent configuration, for example $\{1,0,1,1,1,1,1,0,0\}$, with a performance value $\mathrm{P}_{3}$. Otherwise, if $\mathrm{P}_{1}<\mathrm{P}_{0}$, the firm does not adopt the configuration associated with $\mathrm{P}_{1}$ and explores another configuration, for example $\{0,0,1,1,1,1,1,0,0\}$, with an associated performance $P_{2}$. This process is repeated from $M_{0}$ through

8 - IESE Business School-University of Navarra 
$\mathrm{M}_{30}$. ." In this way, the company engages in local "hill-climbing" or neighborhood search (March and Simon, 1958) towards a peak of the performance landscape.

Control influence can take three forms. As we discussed above, in the Strategic Planning style, control is based mainly on strategic considerations and is therefore focused on a long-term horizon. In Financial Control firms, control is based purely on short-term financial criteria and is not linked to any overall corporate strategic considerations. Finally, Strategic Control firms fall in the middle. Goold et al. state that in Strategic Control firms, results are regularly monitored against explicit strategic performance targets, but "if ... circumstances changed since the plan was made, it is accepted that business managers may not be able to deliver on their original targets and that a revised forecast may be needed. In this way, Strategic Control companies seek a balance between financial and strategic targets." (Goold et al., 1994, p. 414).

We operationalized the three different ways to perform control in the following way:

a) Strategic Planning style. In the simulation model, firms led by the Strategic Planning parenting style evolve, throughout the simulation, through local search within the sub-area of the performance landscape corresponding to the corporate strategy they chose at $\mathrm{M}_{0}$. The majority rule embedded in the chosen corporate strategy bounds choices made within the business units throughout the experiment.

b) Financial Control style. Lacking any initial overall corporate strategy bounding local search processes, firms managed according to this parenting style evolve through local search across the whole performance landscape, without restrictions of any kind.

c) Strategic Control style. Firms managed according to this style strike a balance between longterm strategic objectives and short-term financial ones in the following way. They start their evolution within the discipline provided by the corporate strategy they chose at $\mathrm{M}_{0}$. However, if after a certain number of moves, $\mathrm{T}$, the firm fails to increase its performance, Strategic Control firms abandon the constraints imposed by the majority rule and evolve without restrictions throughout the whole performance landscape. In this way, the failure of the initial corporate strategy to perform leads the firm to focus on an opportunistic evolution led by purely financial criteria. In our study, we modeled two versions of the Strategic Control strategy: $\mathrm{T}=4$ and $\mathrm{T}=8$. This allowed us to observe the performance of "Highly Flexible" firms, which abandon the initial corporate strategy relatively quickly if it does not lead to improved performance $(T=4)$, and of "Moderately Flexible" firms, which abandon their original strategy only after a longer period of failure to improve performance.

\subsection{Modeling environmental dynamism and complexity}

Having discussed the way corporate strategies are chosen by the firms modeled in the agentbased simulation and how these firms evolve through the experiment, in this section we explain our choices of environmental conditions faced by the firms. In this way we will be able to understand how the parenting styles perform in different kinds of environments. Specifically, we modeled scenarios with different degrees of turbulence (Ansoff, 1979). In our model, turbulence is captured by two different dimensions. The first is the degree of environmental

\footnotetext{
ii The number of decisions or "moves" of the simulation was limited to 30, because, as can be seen in Figures 4 to 7 , the performance of the firms is already highly stabilized after roughly 25 moves.
} 
complexity faced by the firm. The second is the degree of environmental dynamism faced by the firm.

\subsubsection{Environmental complexity}

Following recent work based on the performance landscapes framework (Siggelkow and Rivkin, 2005), we consider that environmental complexity is reflected in the interdependence among the decisions that a firm faces. If we assume that interdependences are not chosen by the firm but are dictated by the nature of the decisions themselves, then the complexity of a firm's architectural design reflects the degree of environmental complexity faced by the firm. This assumption is consistent with Ashby's law of requisite varietyiii and Lawrence and Lorsch's Integration and Differentiation framework (Lawrence and Lorsch, 1967). Interdependences between decisions are a consequence of the nature of the decisions themselves and are not chosen by the firm. In our model, therefore, a firm making decisions whose performance contribution has a low degree of interdependence with other decisions is considered to be operating in a simple environment. As the focus of our paper is corporate-level strategy, we operationalized interdependence by tuning the value of parameter $\mathrm{K}_{\mathrm{B}}$, the measure of the level of interdependence between the business units. As stated above, this parameter can take any value between 0 and 1 . Thus, firms with $K_{B}=0$ and $K_{B}=0.25$ are considered to be firms operating in simple environments. Firms with $K_{B}=0$ have an M-form structure (Chandler, 1962), while firms with $K_{B}=0.25$ have a moderately integrated CM-form structure (Hill, 1988). A firm whose decisions are highly interdependent is deemed to be operating in a complex environment. In our model, these are firms for which $K_{B}=0.5$ and $K_{B}=0.75$. These firms represent a highly integrated version of the CM-form structure.

Interdependences within business units are tuned by the parameter $\mathrm{K}_{\mathrm{W}}$. As $\mathrm{K}_{\mathrm{W}}$ is a measure of the number of links between the business units' attributes, with $\mathrm{D}=3$, as in our model, $\mathrm{K}_{\mathrm{W}}$ can take only three values: 0, 1 and 2. Following Simon's treatment of complex problems (Simon, 1996), we assumed that total decomposability is impossible within a single business unit, as the different activities within a single business, such as manufacturing, sales, R\&D, are, by definition, interdependent. Therefore, we discarded cases with $\mathrm{K}_{\mathrm{W}}=0$, due to their lack of realism, and modeled only firms with $K_{W}=1$ and $K_{W}=2$ for each of the four different alternative levels of $K_{B}$ discussed above.

\subsubsection{Environmental dynamism}

Following Mintzberg (1983), we understand environmental dynamism as the extent to which the firm's environment is unpredictable (Mintzberg, 1983). In the model, we operationalize dynamism by tuning the quality of corporate management's cognitive ability at the time of representing the strategic alternatives available for the firm.

Cognition is a forward-looking form of intelligence that is premised on an actor's belief about the linkage between the choice of actions and the subsequent impact of those actions on outcomes. Such beliefs derive from the actor's mental model of the world or "dominant logics"

\footnotetext{
iii The law of requisite variety holds that "control can be obtained only if the variety of the controller ... is at least as great as the variety of the situation to be controlled" (Beer, 1972, cited in Richardson, 1991). Or in Ashby's own picturesque phrasing, "Only variety can destroy variety" (Ashby, 1956, cited in Richardson, 1991).
} 
(Prahalad and Bettis 1986). In contrast, experiential wisdom accumulates as a result of positive and negative reinforcement of prior choices (Levitt and March 1988).

Cognitive representations provide not only a powerful suggestion for an initial choice of organizational form, but also a useful discipline on subsequent efforts at experiential search.

In our paper, we model cognitive representations of two different kinds. The first kind corresponds to firms showing a high degree of awareness of the possible strategies to be followed. This is the case of firms operating in stable environments. In these situations, the different business models are well known and understood and, therefore, corporate choices are clear. We modeled this kind of firms in the following way. At $\mathrm{M}_{0}$, these firms "know" the expected values of all the possible corporate strategies they can choose $(\mathrm{C}=8)$ and adopt the one with the highest associated expected value.

The second kind of cognition represents firms with a poorer understanding of their possible strategic choices. This is typically the case of firms operating in highly dynamic and, therefore, unpredictable environments, where business models are in rapid flux. We modeled this kind of firms by letting them represent only the value of a fraction of all the corporate strategies available $(\mathrm{C}=3)$. Firms then choose the best one out of the ones it can represent from this limited sample.

Figure 2 summarizes the discussion of turbulence and shows the four different kinds of environments included in the simulation experiment, as well as the detailed modeling choices comprehended within them. Note that firms following the Financial Control parenting style are not led by any corporate strategy; therefore, making distinctions between the quality of corporate representations is meaningless for the modeling of this style.

Figure 2. Modeling different environments

\section{Environmental Dynamism}

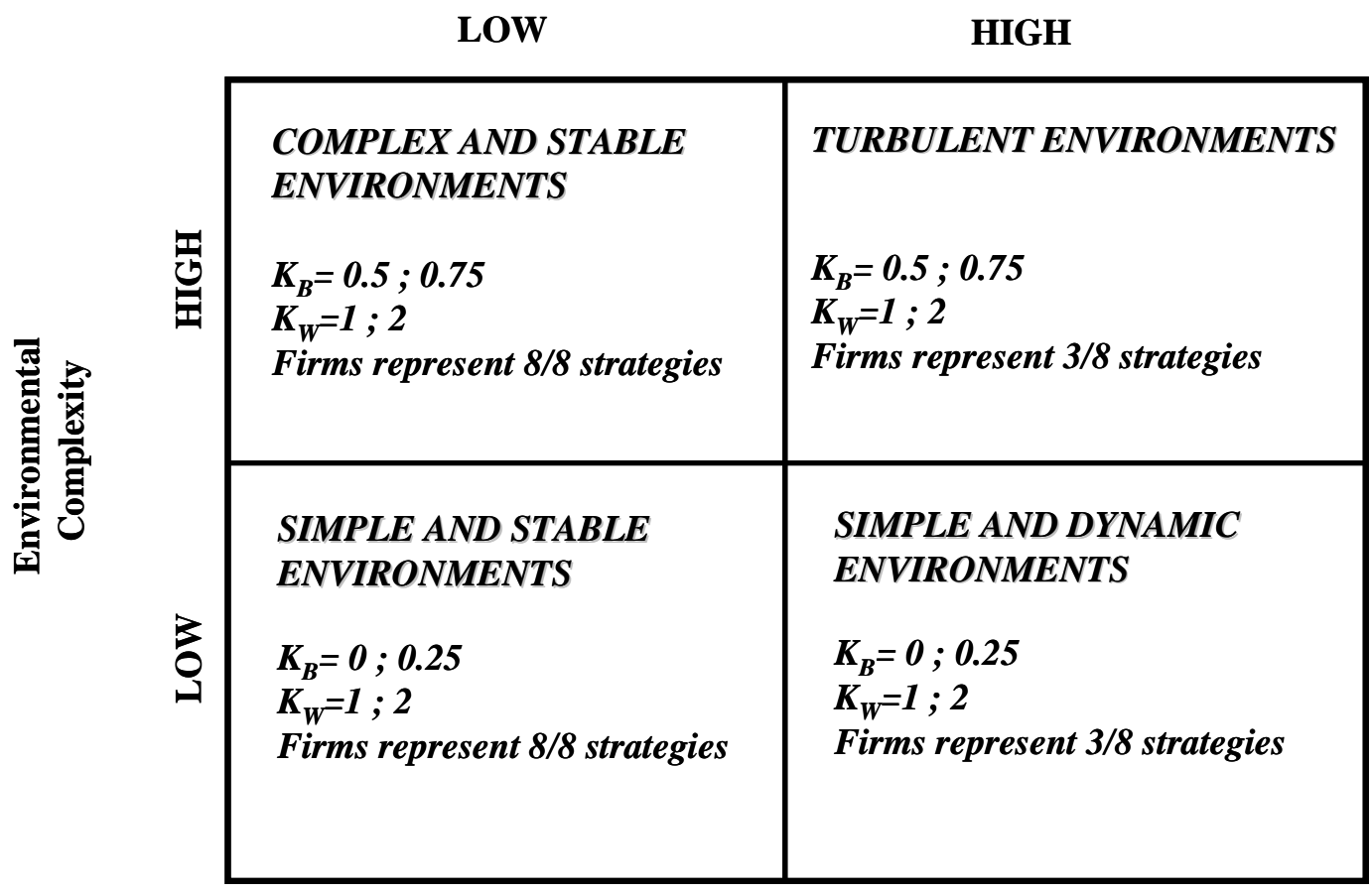




\section{Architecture of the Simulation}

In Figure 3, adapted from Caldart and Ricart's Corporate Strategy Triangle (Caldart and Ricart, 2004), we integrate and synthesize our discussion on the modeling of parenting styles by representing the three building blocks that constitute our agent-based model of Corporate Strategy. These building blocks are, first, a cognitive representation of the alternative strategies that the firm can choose in its performance landscape. Second, a corporate search strategy, defined by the parenting style (planning influence and control influence) followed by the firm. Finally, the corporate strategy is completed by choosing an architectural design reflecting the level of environmental complexity faced by the firm.

Figure 3. Corporate Strategy triangle (adapted from Caldart and Ricart, 2044)

Cognitive Representation High awareness of strategic alternatives Low awareness of strategic alternatives

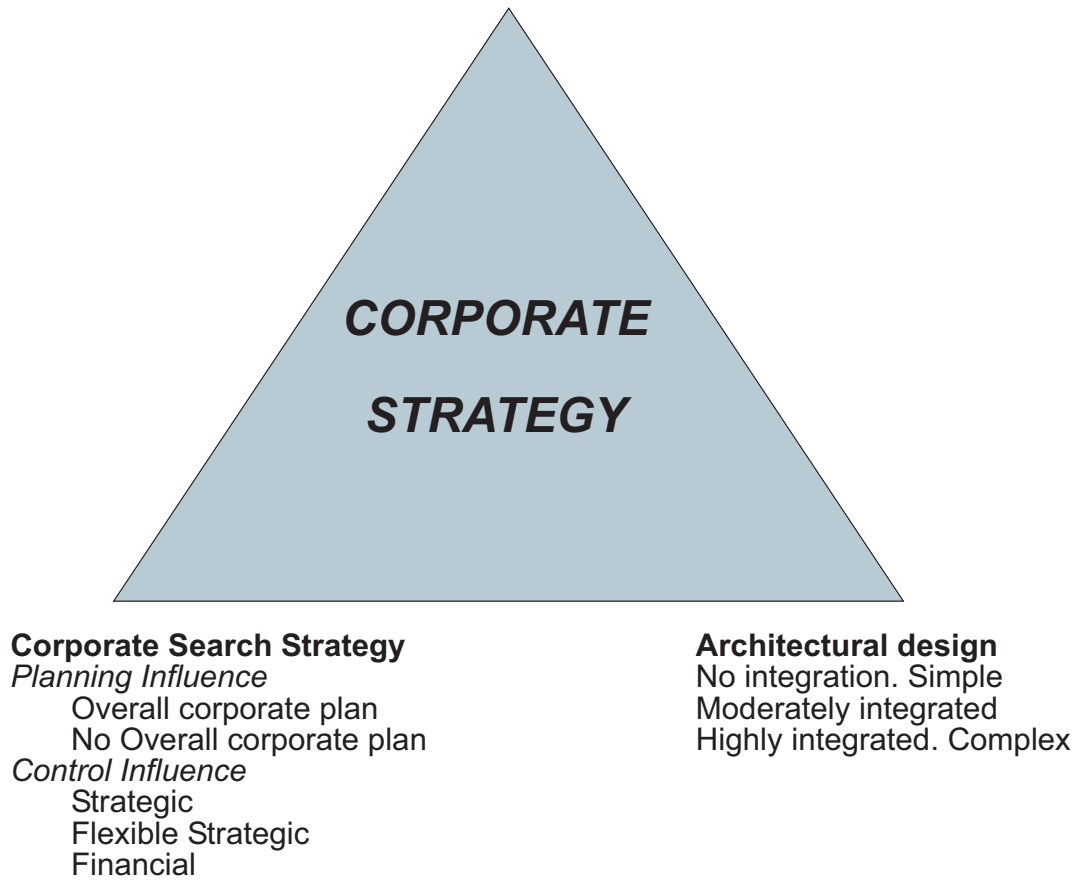

When agents use adaptive rather than optimizing strategies, the consequences of such adaptive processes are very difficult to deduce when there are many interacting agents following rules that have non-linear effects (Axelrod, 2005). Therefore it is necessary to study the problem with the aid of simulation.

In Table 2 we list the different kinds of firms included in the simulation model, specifying our modeling choices regarding the three building blocks of corporate strategy illustrated by Figure 3. It can be noted that firms were grouped in eight "families". Each family corresponds to a different topography of the performance landscape, i.e., the different combinations of the parameters $K_{B}$ and $K_{W}$ included in the model. 
Table 2. Description of families of firms included in the simulations

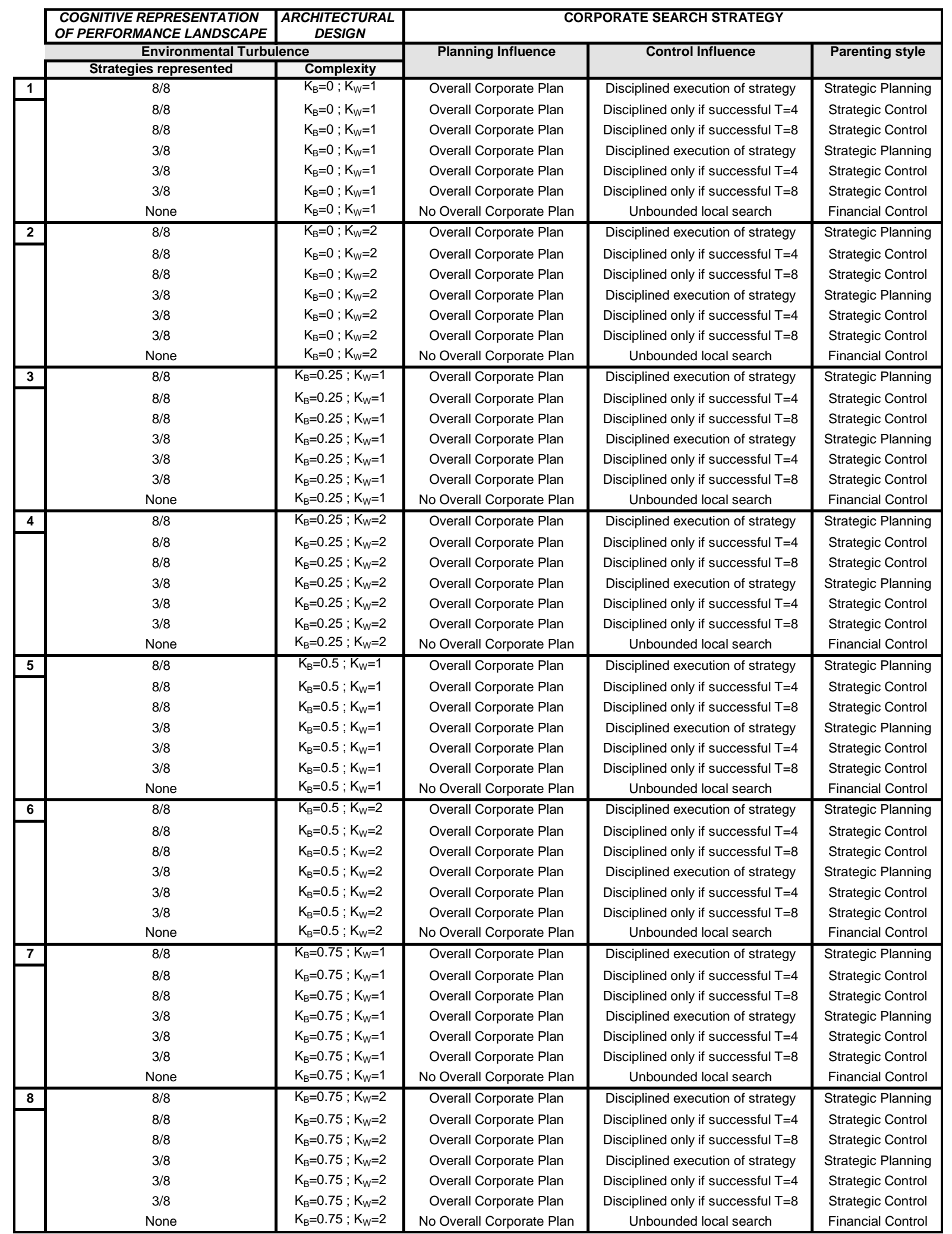


In order to ensure that the results reflect the underlying structure of the simulation model and not just particular cases of a highly stochastic process, we proceeded in the following way. For every set of parameters $\mathrm{K}_{\mathrm{w}}$ and $\mathrm{K}_{\mathrm{B}}$ a landscape is generated. In that landscape, 25 firms of each of the seven kinds of firms corresponding to the chosen set of parameters are released during the 30 "moves". The average performance value for each kind of firms in each period is recorded in that landscape. Then, another landscape is generated and another seven sets of 25 firms are released. This operation is repeated for 500 landscapes. This process is repeated for all of the eight families of landscapes corresponding to all the combinations of the parameters $\mathrm{K}_{\mathrm{W}}$ and $K_{B}$ included in Table 2 above. Therefore, for every set of parameters, the performance value of each kind of firms will be composed of the average of 500 experiments on different fitness landscapes, each averaging 25 firms per type of evolution pattern.

\section{Analysis}

Table 3 describes the performance of each corporate style for each of the four kinds of environments defined in Figure 2 above ${ }^{\mathrm{iv}}$. Table 4 shows the differences, in percent, between the most successful style and the rest of the styles for the different kinds of environment.

Table 3. Simulation results

\section{Environmental Dynamism}

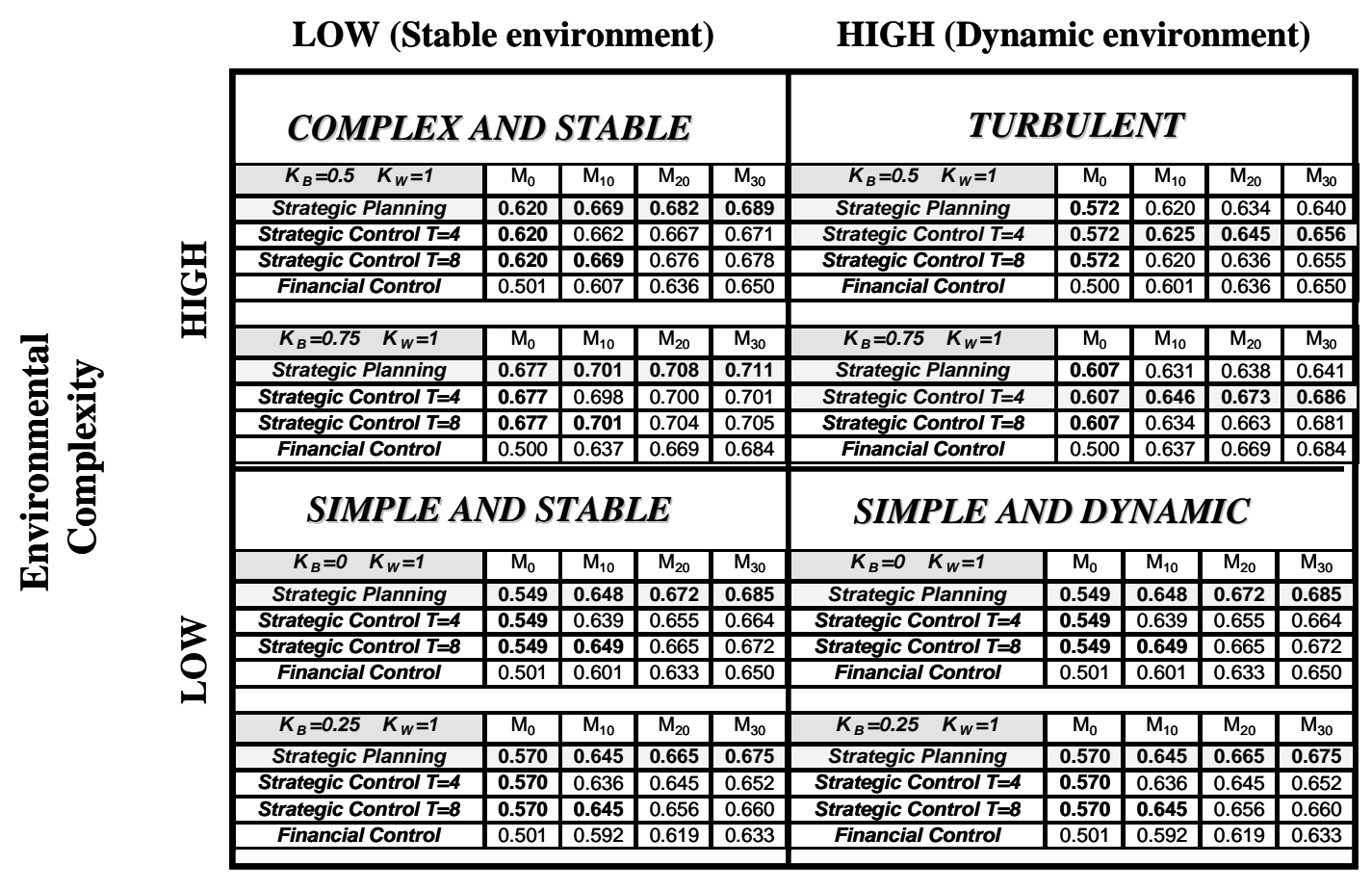

\footnotetext{
iv The results reported correspond to $K_{W}=1$. We also modeled the same firms for $K_{W}=2$, but for the sake of simplicity we did not include them in the table as they are consistent with those for $\mathrm{K}_{\mathrm{W}}=1$.
} 
Table 4. Differences in performance with respect to the best strategy

\section{Environmental Dynamism}

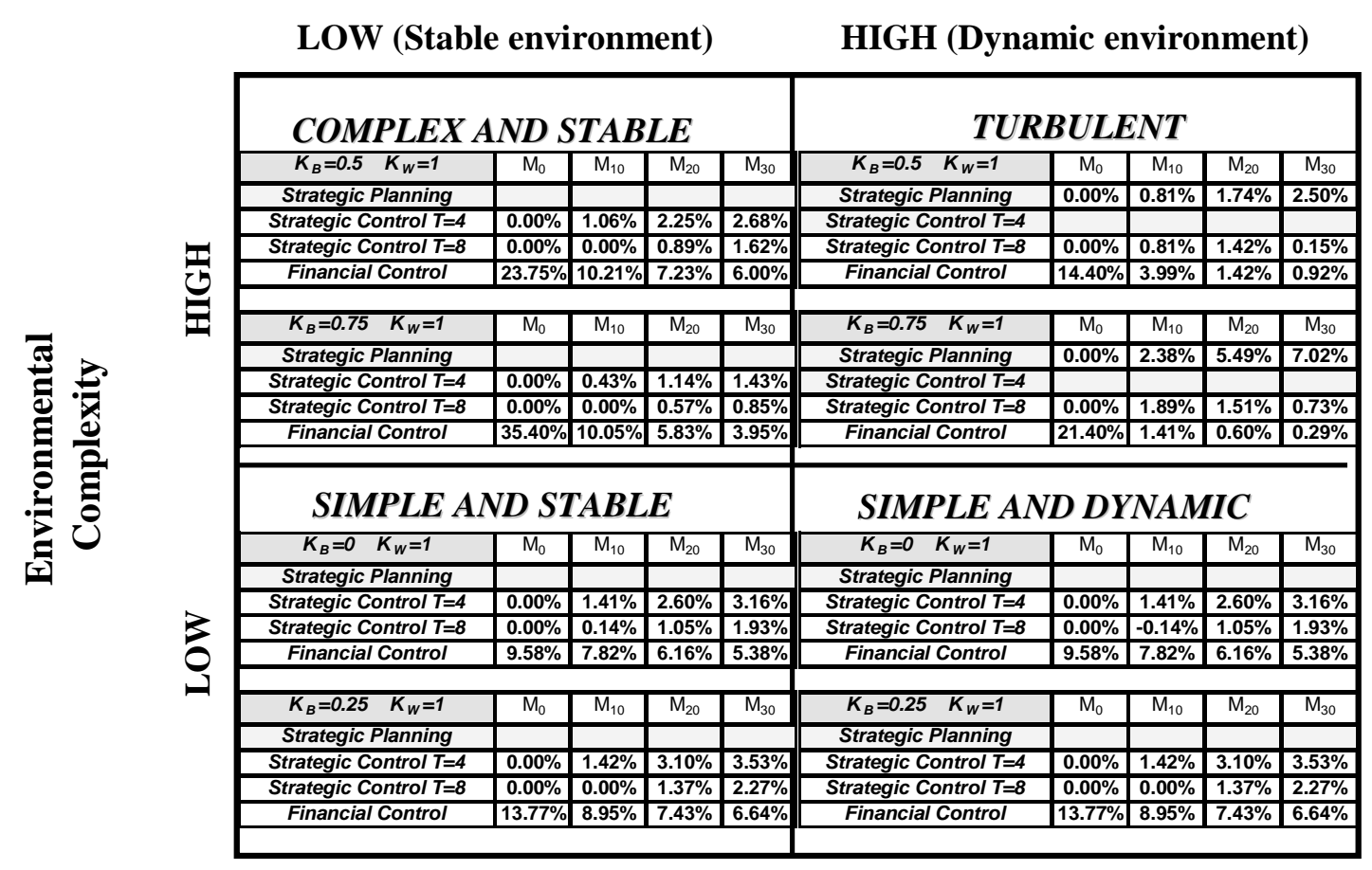

Simple and Stable environments. Strategic Planning (SP) shows the best performance when complexity is low and the cognitive representations of corporate management are sophisticated due to the predictability of the firm's environment. Although Strategic Control (SC) firms start from the same level as SP firms, they "pay" for their opportunistic departure from their initial corporate strategy by edging away from SP once they start to pursue strategic explorations outside their original focus. Consistent with these results, the Moderately Flexible SC case $(T=8)$ outperforms the Highly Flexible SC strategy $(\mathrm{T}=4)$. Financial Control $(\mathrm{FC})$ firms improve fast but cannot compensate for their initial disadvantage, due to the fact that they do not rely on any planning influence, and show the poorest performance. These results were consistent for different levels of interdependence within each of the business units, i.e., for $\mathrm{K}_{\mathrm{W}}=1$ and $\mathrm{K}_{\mathrm{W}}=2$.

Complex and stable environments. As in the previous case, these kinds of environments show a high degree of stability, allowing firms to have a deep understanding of the alternative corporate strategies to pursue and their performance implications. However, the increased complexity of the environment obliges companies to develop a higher level of interdependence between the decisions made by different business units $\left(K_{B}=0.5\right.$ and $\left.K_{B}=0.75\right)$.

Results follow the same pattern as in the Simple and Stable quadrant discussed above. SP is the most rewarding strategy, both for $K_{B}=0.5$ and $K_{B}=0.75$, with $K_{W}=1$ and $K_{W}=2$. In Table 4, however, we can see that, especially for $K_{B}=0.75$, the gap between the performance of SP and the two SC styles narrows with respect to the previous case. The gap between the two SC variants also narrows. In these kinds of environments, FC is again the poorest style to follow.

Simple and Dynamic Environments. In these environments, the dynamism of the environment limits managers' ability to develop a clear representation of all the strategic options available to the firm. In cases combining dynamism with low levels of complexity $\left(K_{B}=0\right.$ and $\left.K_{B}=0.25\right)$, the 
SP style again shows the strongest performance. In the case of $K_{B}=0.25$ (CM-form), however, the gaps between the results of SP and SC are narrower than in the Complex and Stable quadrant, indicating that the decision to be opportunistic can lead to almost the same result as disciplined SP. For $K_{B}=0.25$ and $K_{W}=1$, the difference in performance at $M_{30}$ is only $0.47 \%$, compared to differences ranging from $0.85 \%$ to $2.27 \%$ in the environments discussed above.

Turbulent Environments. In environments characterized by high complexity and dynamism, the relative performance of the different styles varies substantially with respect to the cases discussed above. In these environments, flexibility seems to be more critical as a key success factor. In turbulent environments, the Highly Flexible SC style, which scored $3^{\text {rd }}$ in the three environments discussed above, is the top performer, followed by the Moderately Flexible style in the less interdependent case $\left(K_{B}=0.5\right)$. As $K_{B}$ increases, FC's performance increases because flexibility becomes a valuable feature in environments where cognition is poor and complexity makes evolution more difficult due to the increased ruggedness of the landscape. FC ranks $2^{\text {nd }}$ and very close to SC $(T=4)$. In both cases, SP, the most rewarding style in the previous three quadrants, shows the poorest performance ( $7.02 \%$ below the best style for $K_{B}=0.75$ and $K_{W}=1$ at $M_{30}$ )

Our findings can be summarized as follows. In environments characterized by a low level of complexity and high predictability, the discipline embedded in the Strategic Planning style is a valuable feature (Figures 4 and 5). Good strategy formulation gives a firm a decisive advantage over rivals following more opportunistic approaches. Moreover, low complexity makes it easier for the firm to evolve through local search, thus limiting the potential downsides of the lack of strategic flexibility (control influence based on long-term strategic criteria). A Strategic Control style firm cannot overcome through higher flexibility the loss of a well grounded initial strategic direction, this gap becoming smaller as complexity, measured by $\mathrm{K}_{\mathrm{B}}$ and $\mathrm{K}_{\mathrm{W}}$, increases. Indeed, the Moderately Flexible SC outperformed the Highly Flexible SC style. The worst strategy was Financial Control, as it cannot overcome through its maximum flexibility the decisive disadvantage resulting from the fact that its initial position is not based on strategic intelligence but merely random choice. However, it is worth mentioning that the higher $\mathrm{K}_{\mathrm{B}}$ and $\mathrm{K}_{\mathrm{W}}$ become, the closer the Financial Control style gets to catching up with the other styles.

Figure 4. Simple and Stable Environment $\left(K_{W}=1\right.$ and $\left.K_{B}=0\right)$

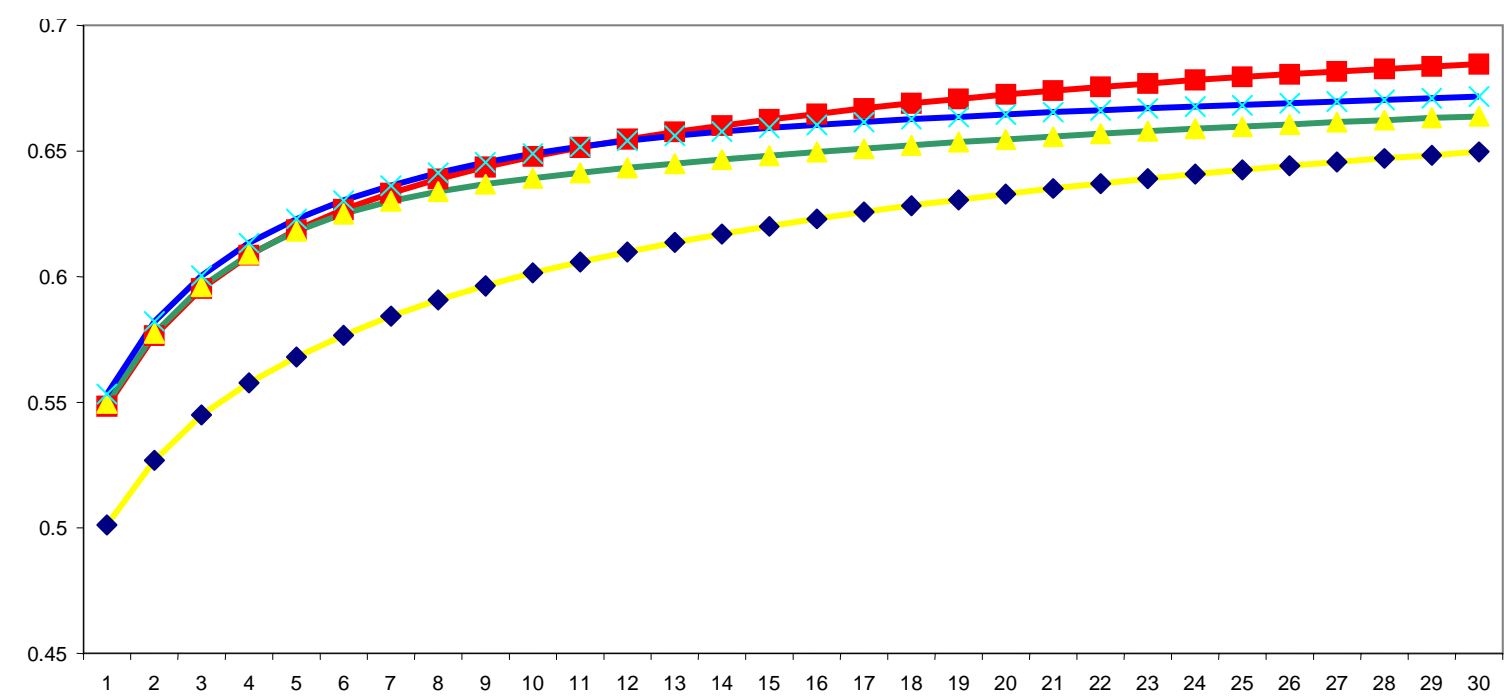




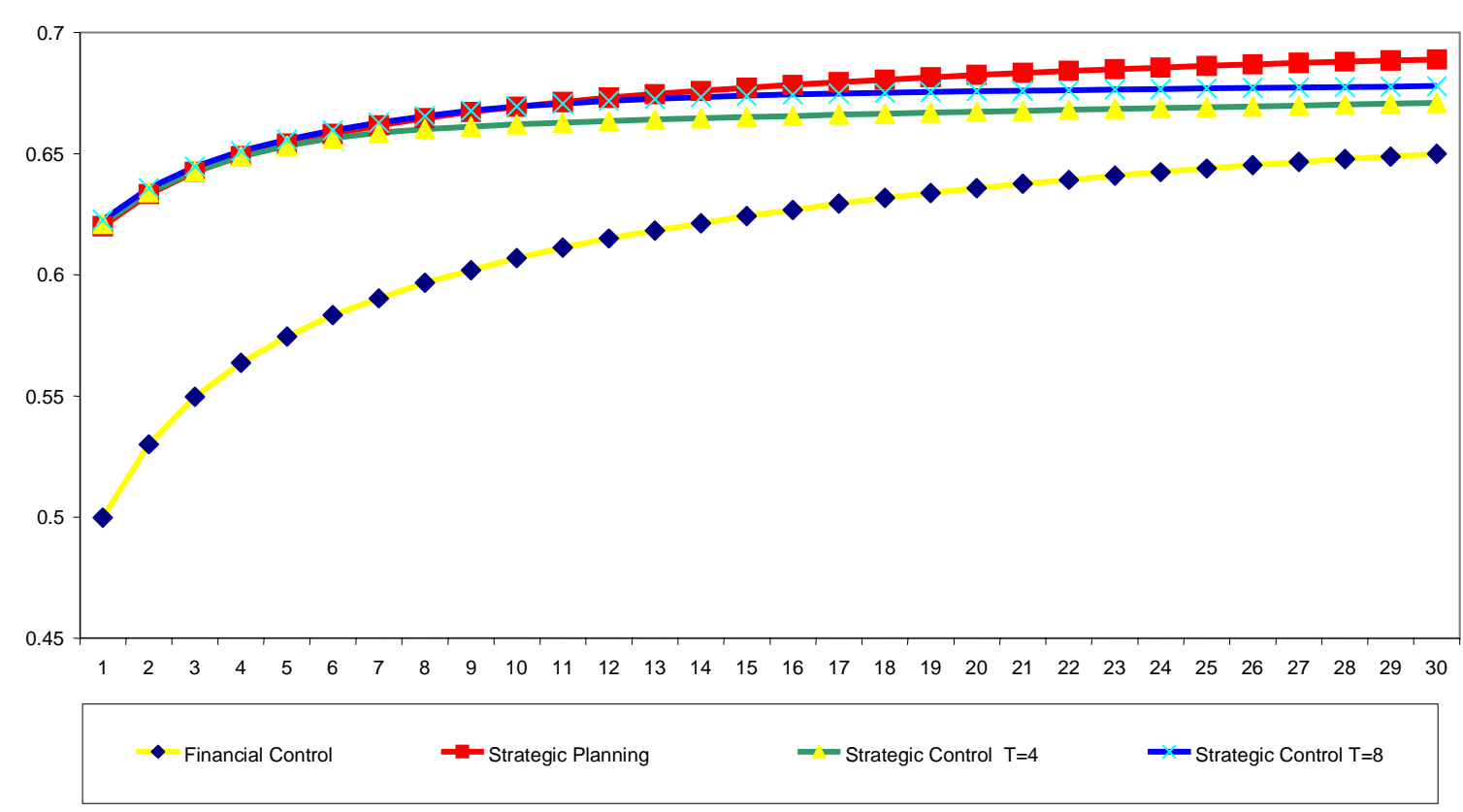

The situation changes radically when the complexity of the architectural design is relatively high or high (Figures 6 and 7). In these cases, the relative performance of firms is contingent upon the level of environmental dynamism. For stable environments, the different styles rank as in low complexity environments. But although the trade-off between the benefits of disciplined execution of a well formulated strategy and the benefits of strategic flexibility continue to favor the former, the gap between the two is narrower.

In dynamic environments $\left(K_{B}=0.5\right.$ and $\left.K_{B}=0.75\right)$, the results of the trade-off between discipline and flexibility invert radically. The best results belong to the SC Highly Flexible style, a strategy that rapidly sacrifices strategic discipline if the firm fails to make consistent progress in the short term. Not surprisingly, in this context the combination of a rigid strategy led by poor cognition and the difficulty of evolving due to the high suppressing effects ${ }^{v}$ embedded in a complex architectural design make the SP style the poorest performer in the four types of firms modeled. Even the initially "blind" FC Style outperforms SP very easily. Lack of flexibility to adapt to the relatively unknown environment combined with a complex architectural design with high suppressing effects hamper the ability of Strategic Planning firms to perform effectively in Turbulent environments. ${ }^{\text {vi }}$

\footnotetext{
"A strategic change is said to suffer suppressing effects when there is a side-effect or "backfire" to that initiative that prevents it from achieving the intended effects. For instance, by increasing the length of production runs a firm may gain in manufacturing cost efficiency, yet sales may be lost as a result of the firm's reduced ability to respond quickly to changes in demand, thus offsetting the impact of increased operational efficiency on profits.

${ }^{\text {vi }}$ We also modeled firms with $K_{B}=0.25$ and $K_{B}=0.75$. We observed that the strength of disciplined strategies fades progressively as interdependencies increase.
} 
Figure 6. Simple and Dynamic Environment

$\left(K_{w}=1\right.$ and $\left.K_{B}=0.5\right)$

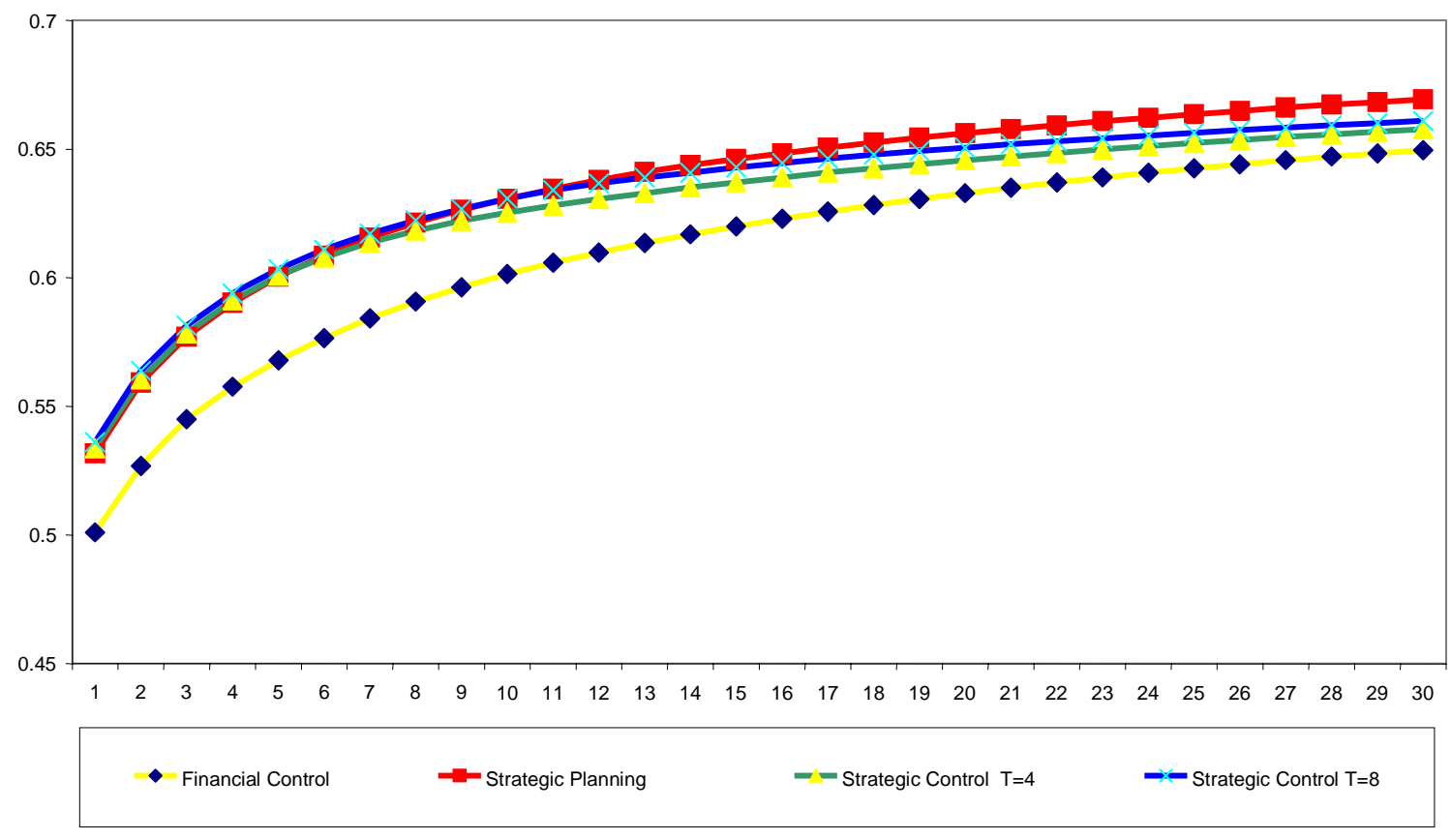

Figure 7. Turbulent Environment $(K W=1$ and $K B=0.5)$

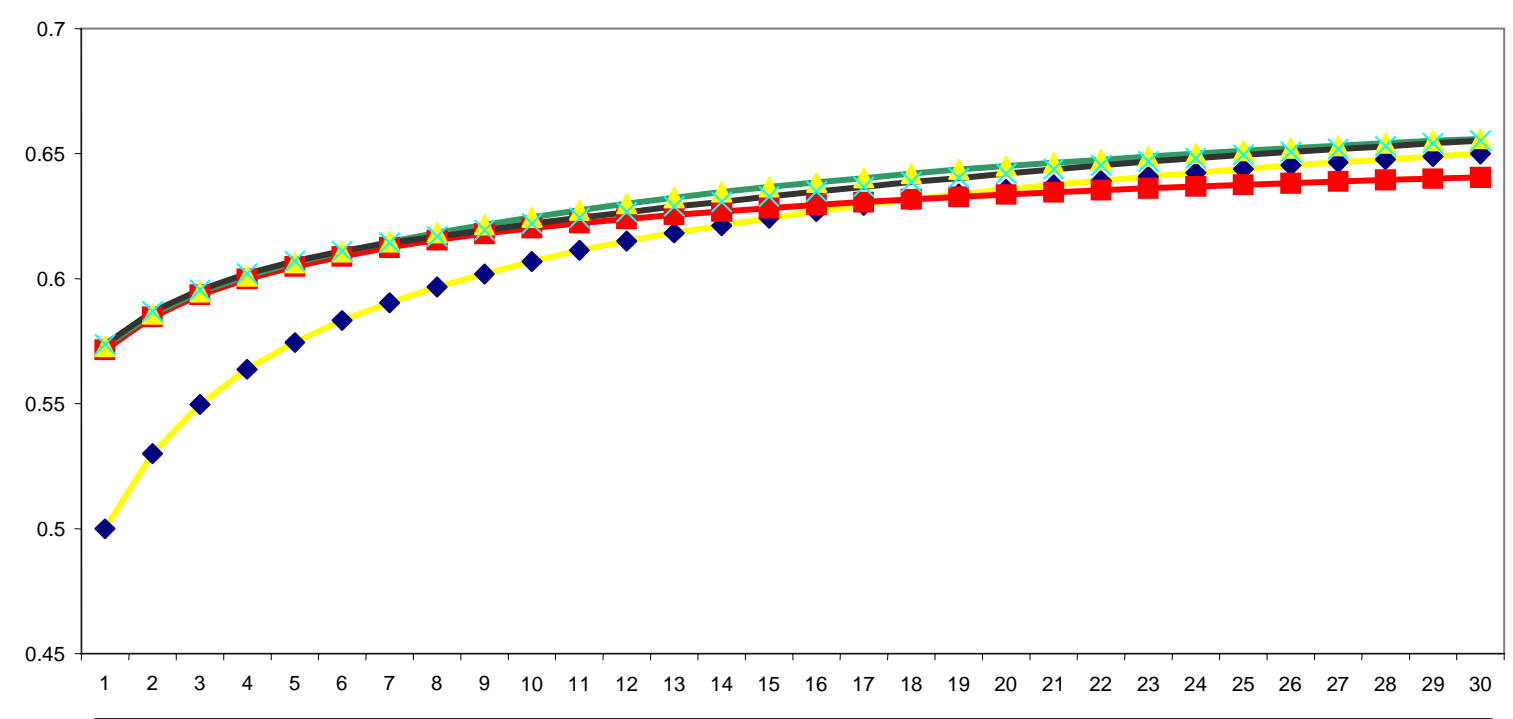




\section{Discussion and Conclusions}

The purpose of this paper was to provide a formal test of Goold et al.'s (1987) parenting styles, a widely accepted way of describing the broad patterns followed by corporate managers in leading their multibusiness firms. Parenting styles differ in their planning influence centralized (high influence) or decentralized (low influence)- and their control influence -based on strategic or financial criteria. We opted to approach the topic innovatively using an agentbased simulation model using the performance landscapes framework. Agent-based simulations based on Kauffman's NK model allow us to model how emerging properties of an evolving entity derived from interaction between its different parts affect its performance. Thus, they constitute a modeling strategy that narrows the gap between closed-form solutions that consider firms as omnisciently rational entities and descriptions from empirically grounded theory.

This modeling strategy allows us to model firms as adaptive rational systems, as described by Cyert and March (1963). By approaching organizational problems through this modeling strategy we improve our understanding of how the features that constitute a parenting style interact and affect the firm's performance as its adaptive process unfolds. With our model we can distinguish the relative performance of the different styles in four different kinds of environments that vary in complexity and dynamism. This proved to be a relevant distinction, as results show that the relative performance of the different parenting styles in turbulent environments were radically different from their performance in the rest of the environments.

Our results also have implications for the debate on planning vs. emergence (Mintzberg, 1990, Ansoff, 1991). They suggest that in stable environments, Porter's (1996) advice to strategic leaders to resist "constant pressures to compromise, relax trade-offs and emulate rivals" (pg. 77) is sound. Given a deep knowledge of their competitive arenas (in our study, "performance landscapes") and the ability to easily evolve incrementally when complexity is low, SP firms outpace rivals that engage in varying degrees of opportunistic behavior (SC) or that completely lack overall corporate planning (FC). Environmental stability enables firms to formulate strategies led by cognitive representations based on a deep knowledge of the cause-effect relationships embedded in their strategic choices, leading to higher expected performance. These situations are consistent with the rational tradition of strategic planning embedded in the design, planning and positioning schools of strategy (Mintzberg, Ahlstrand and Lampel, 1998).

As the environment becomes more dynamic, however, this situation changes substantially. Dynamism limits managers' ability to adequately represent the firm's strategic options. As stated above, poor representations coupled with high complexity make strategies based on a very disciplined execution of the strategy as initially formulated the worst possible option. Given the widespread agreement among academics and practitioners that business environments are becoming increasingly dynamic and complex (D'Aveni, 1994; Day and Reibstein, 1997; Eisenhardt and Brown, 1998; Normann, 2001; Galbraith, 2002), these conclusions are especially relevant, as what we have labeled "turbulent" environments are precisely the kind of environments found in an increasing number of industries today.

This conclusion is consistent with Brews and Hunt's (1999) empirical finding that as environmental instability grows, so does planning flexibility. However, our results are not a case in favor of purely emergent approaches. We found that in turbulent environments the best style is Strategic Control, a strategy based on an overall initial plan and the flexibility to

IESE Business School-University of Navarra - 19 
abandon it opportunistically under certain circumstances. This style always outperforms Financial Control strategies having maximum adaptive flexibility but no initial positioning intelligence. These results are consistent with Mintzberg's (1994) notion of Realized Strategy as a synthesis of an intended strategic direction and the flexibility to address relevant emergent aspects.

These insights also have important implications for organizational design. Our simulations show that the performance of a firm facing a complex environment and therefore having a highly interdependent architectural design, such as a highly interdependent CM-form or a matrix structure, is highly contingent on the quality of the cognitive representation that drives the corporate strategy. While it is obviously non-trivial to distinguish ex-ante in particular cases whether a company has a sophisticated or a rough understanding of its competitive landscape, it is important to know that the more complex the organizational form, the more risky it will be to adhere rigidly to an established strategic plan. The complexity of highly interdependent structures makes incremental change more difficult, increasing the risk that the firm might suffer a "complexity catastrophe" (Kauffman, 1993; Brown and Eisenhardt, 1998), i.e., the inability to evolve successfully as a result of the constraints imposed by the suppressing effects of its highly interdependent design. If these firms chose to adopt an M-form, the quality of corporate cognition would be less critical for their performance, as the lower ruggedness of their landscape eases their adaptive evolution process. Even so, for a firm having related businesses and operating in a highly turbulent environment, adopting an M-form might lead to an "error catastrophe" (Kauffman, 1993; Brown and Eisenhardt, 1998) or failure to address the degree of complexity of the environment. If a firm has a cluster of highly related and, therefore, highly interdependent businesses (as they demand close coordination for activity and knowledge sharing), it will need to find a balanced organizational design that addresses the needs of knowledge and activity sharing without provoking a complexity catastrophe. Thus, these findings give formal and more general support to insights provided by case study-based research that prescribes the superiority of emergent approaches for corporate value creation (Eisenhardt and Brown, 1998; Chakravarthy, Zaheer and Zaheer, 2001; Galunic and Eisenhardt, 2001; Goold and Campbell, 1999, 2002; Helfat and Eisenhardt, 2004). Emergent "self organized" interdivisional cooperation initiatives are, by definition, loosely coupled, i.e., less demanding in terms of the interdependences they create across units. By contrast, centrally imposed interdivisional collaboration initiatives tend to be formally structured, generating tight couplings affecting business units sometimes regardless of the real need for interdivisional collaboration (Goold and Campbell, 1999). These situations increase interdependences unnecessarily, with the proliferation of coordination meetings, "ad hoc" reporting requirements, etc.

Self-organized, loosely-coupled collaboration initiatives offer a hope for managers who struggle to navigate between the "Scylla and Charibdes" resulting from either naively simple designs that fail to address environmental variety, or unnecessarily complex ones showing very high suppressing effects. An architectural design that relies more strongly on self-organized interdependence at the business unit level allows firms to "economize" on organizational interdependencies while still achieving the potential for synergy development resulting from interdivisional activity sharing and knowledge transfer. 


\section{Limitations and Directions for Future Research}

Agent-based simulations based on adaptations of Kauffman's NK model are an insightful way to describe the broad patterns observed in the evolution of a boundedly rational agent's strategy in a setting affected by non-linearly related variables.

However, as Kauffman's model was originally developed in the context of the natural sciences, organizational scholars using this technique must make major efforts to introduce features of organizational life that are completely absent in the original formulation of the model. Recent work (Gavetti, Levinthal and Rivkin, 2005; Siggelkow and Levinthal, 2003; Siggelkow and Rivkin, 2005; Lenox, Rockart and Lewin, 2004; Siggelkow and Levinthal, 2005) has taken valuable steps in this direction.

Our study in particular does not address important features of firm evolution, such as the fact that firms can learn more alternative strategic options "on the road". Furthermore, our research depicts evolutionary processes, while firms are actually involved in a coevolutionary process, interacting with other entities whose interaction alters the topography of the performance landscape, making adaptive evolution more challenging and difficult to predict.

Further research in this field based on simulation studies could benefit from addressing these issues and others such as the introduction of bounded rationality in performance evaluation and the implications of proactive vs. failure-induced application of new learning. 


\section{References}

Andrews, K. 1971. The Concept of Corporate Strategy. Burr Ridge, IL: Dow-Jones, Irwin.

Ansoff, H.I. 1991. "Critique of Henry Mintzberg's 'The design school: Reconsidering the basic premises of strategic management'." Strategic Management Journal, 12: 449-461.

Bowman, E., and Helfat., C. 2001. "Does corporate strategy matter?" Strategic Management Journal, 22: 1-23.

Brabazon, T., and Matthews, R. 2002. "Organizational adaptation on rugged landscapes." Working paper.

Brews, P.J., and Hunt, M.R. 1999. "Learning to plan and planning to learn: resolving the Planning School/Learning School debate.” Strategic Management Journal, 20: 889-913.

Brown, S., and Eisenhardt, K. 1998. Competing on the Edge: Strategy as Structured Chaos. Cambridge: Harvard Business School Press.

Brush T., and Bromiley, P. 1997. "What does a small corporate effect mean? A variance components simulation of corporate and business effects." Strategic Management Journal, 18: 825-835.

Caldart, A., and Ricart, J. E. 2004. "Corporate strategy revisited: A view from Complexity Theory.” European Management Review, 1: 96-104.

Chakravarthy B., Zaheer, A., and Zaheer S. 2001. "Knowledge sharing in organizations: A field study." Paper presented at the Strategic Management Society Conference (October), San Francisco.

Chandler Jr., A. 1962. Strategy and Structure. Cambridge: MIT Press.

Chang S., and Singh, H. 2000. "Corporate and industry effects on business unit competitive position.” Strategic Management Journal, 21: 739-752.

Collis, D., and Montgomery., C. 1998. "Creating corporate advantage." Harvard Business Review, 76: 71-83.

Cyert, R., and March, J. 1963. A Behavioral Theory of the Firm. New Jersey: Prentice Hall.

D'Aveni, R. 1994. Hyper Competition. Managing the Dynamics of Strategic Maneuvering. New York: Free Press.

Day, G., and Reibstein, D. 1997. Wharton on Dynamic Competitive Strategy. New York: John Wiley and Sons, Inc.

De Wit, B., and Meyer, R. 2005. Strategy Synthesis. Resolving Strategy Paradoxes to Create Corporate Advantage. London: Thomson.

Galbraith, J. 2002. Designing Organizations. An Executive Guide to Strategy, Structure and Process. San Francisco: Jossey Bass.

Galunic, C., and Eisenhardt, K. 2001 "Architectural innovation and modular corporate forms." Academy of Management Journal, 44: 1229-1250.

Gavetti, G. 1999. "Cognition, capabilities and corporate strategy making." Working paper, Harvard Business School, Cambridge.

Gavetti, G., and Levinthal, D. 2000. "Looking forward and looking backward: cognitive and experiential search.” Administrative Science Quarterly, 45: 113-137. 
Gavetti, G., Levinthal, D., and Rivkin, J. 2003. "Strategy-making in novel and complex worlds: The power of analogy." Working paper, Harvard Business School, Cambridge.

Goold M., and Campbell, A. 1987. Strategies and Styles. Oxford: Blackwell.

Goold M, Campbell. A., and Alexander M. 1994. Corporate Level Strategy. Creating Value in the Multibusiness Company. Chichester: John Wiley and Sons.

Goold, M., Campbell, A., and Alexander, M. 1994. "Corporate strategy: The quest for parenting advantage." Harvard Business Review, 95: 120-132.

Goold, M., and Campbell, A. 1999. "Desperately seeking synergy." Harvard Business Review, 77: 131-143.

Goold, M., and Campbell, A. 2002. Designing Effective Organizations: How to Create Structured Networks. Jossey Bass.

Grant, R. 2005. Contemporary Strategy Analysis. Oxford: Blackwell Publishing.

Helfat, C., and Eisenhardt, K. 2004. "Intertemporal economies of scope, organizational modularity and the dynamics of diversification.” Strategic Management Journal, 25: 1217-1232.

Hill, C. 1988. "Internal capital market control and financial performance in multidivisional firms." The Journal of Industrial Economics, 37: 67-83.

Kauffman, S. 1993. The Origins of Order. New York: Oxford University Press.

Lawrence, P., and Lorsch, J. 1967. Organization and Environment. Managing Differentiation and Integration. Cambridge, MA: Harvard Business School Press.

Lenox, M., Rockart, S, and Lewin, A. 2004. "Complementarities, competition, and sustained intra-industry heterogeneity in profits." Working paper, Fuqua School of Business, Durham, NC.

Levinthal D. 1997. “Adaptation in rugged fitness landscapes.” Management Science, 43: 934950.

Levinthal D., and Warglien M. 1999. "Landscape design: designing for local action in complex worlds.” Organization Science, 10: 342-357.

Levitt, B., and March, J. 1988. “Organizational learning.” Annual Review of Sociology, 14: 319340.

March, J., and Simon, H. 1958. Organizations. New York: John Wiley \& Sons.

Markides C., and Williamson. P. 1994. "Related diversification, core competences and corporate performance." Strategic Management Journal, 15: 149-165.

McGahan A., and Porter., M. 2002. "What do we know about variance in accounting profitability?” Management Science, 48: 834-851.

McKelvey, B. 1999. "Avoiding complexity catastrophe in coevolutionary pockets: strategies for rugged landscapes." Organization Science, 10: 294-321.

Milgrom P., and Roberts J. 1992. Economics, Organization and Planning. New York: Prentice Hall.

Mintzberg, H. 1990. "The design school: reconsidering the basic premises of strategic management." Strategic Management Journal, 11: 171-195. 
Mintzberg, H., Ahlstrand, B., and Lampel, J. 1998. Strategy Safari: A Guided Tour Through the Wilds of Strategic Planning. London: Prentice Hall.

Nelson, R., and Winter, S. 1982. An Evolutionary Theory of Economic Change. Cambridge: Bellknap Press.

Normann, R. 2001. Reframing Business. When the Map Changes the Landscape. Chichester: John Wiley and Sons.

Porter, M. 1980. Competitive Strategy. Techniques for Analyzing Industries and Competitors. New York: The Free Press.

Porter, M. 1987. "From competitive advantage to corporate strategy." Harvard Business Review, 65: 43-59.

Porter, M. 1996. "What is strategy?” Harvard Business Review, 74: 61-78.

Prahalad, C., and Bettis, R. 1986. "The dominant logic: A new linkage between diversity and performance.” Strategic Management Journal, 7: 485-501.

Prahalad, C., and Hamel, G. 1990. "The core competences of the corporation." Harvard Business Review, 68: 79-91.

Richardson, G. 1991. Feedback Thought in Social Science and Systems Theory. Philadelphia: University of Pennsylvania Press.

Rivkin, J. 2000. “Imitation of complex strategies.” Management Science, 46: 824-844.

Ruefli, T., and Wiggins, R. 2003. "Industry, corporate and segment effects and business performance: a non-parametric approach.” Strategic Management Journal, 24: 861-879.

Siggelkow, N., and Levinthal, D. 2003. "Temporarily divide to conquer: centralized, decentralized, and reintegrated organizational approaches to exploration and adaptation." Organization Science, 14: 650-669.

Siggelkow, N., and Levinthal, D. 2005. "Escaping real (non-benign) competency traps: linking the dynamics of organizational structure to the dynamics of search." Strategic Organization, 3: 85-115.

Siggelkow, N., and Rivkin, J. 2005. "Speed and search: Designing organizations for turbulence and complexity." Organization Science, 16: 101-122.

Simon, H. 1996. The Sciences of the Artificial. Cambridge: The MIT Press.

Simon, H. 1997. Administrative Behavior. New York: Free Press. 